\title{
THE ELECTROENCFPHALOGRAM AND THE SITE OF ACTION OF PENTAZOCINE ON THE BRAIN
}

\author{
Hisashi Yanagida, M.D. ${ }^{*}$ and Hideo Yamamura, M.D. $\dagger$
}

IT Is Now a well established fact that pentazocine produces an analgesic state in therapeutic doses, ${ }^{1-7}$ and it has been widely used as a supplement in nitrous oxide oxygen-relaxant anaesthesia. ${ }^{8}$ The respiratory and circulatory effects of pentazocine have been described by many people, $?^{3-14}$ and are well known.

Although the electroencephalogram (EEG) has been used as a monitor of anaesthetic plane, the effect of pentazocine has not yet been established. During the course of our research, we came to realise that, in clinical cases under nitrous oxide-oxygen-relaxant anaesthesia the EEG changed to low voltage fast activity after administration of pentazocine intravenously. However, it was not clear that the FFG change was due to the pharmacological action of pentazocine, because FEC patterns are easily changed by various factors during anaesthesia. ${ }^{15}$

The present study was aimed at resolving the following points: (1) the FEG pattern following the administration of pentazocine, (2) the EEG in nitrous oxideoxygen-relaxant anaesthesia combined with pentazocine and (3) the subcortical site's which might prove more sensitive to the action of pentazocine.

\section{Methons}

The studies were performed on volunteers, clinical patients, and animals.

\section{VOLUNTEERS}

The subjects were five healthy young men who volunteered for a study of their EEG after administration of pentazocine $(15 \mathrm{mg})$ intravenously. They rested for at least 20 minutes breathing air in a quiet and darkened room. The scalp electrodes for the recording of the EEG were placed on the both sides of the frontal, parietal and occipital areas, and the EEG was recorded before and after administration of pentazocine.

\section{Clinical Study}

Fourteen patients, ranging in age from 20 to 36 years, who were scheduled for lower limb surgery, were selected for the study. They were ascertained to be free from known respiratory, cardiovascular or mental disease. No preoperative medication was given in preparation for the surgical procedure. The subjects were divided into two groups:

"Department of Anesthesiology, University of Tokyo School of Medicine, Tokyo, Japan.

$\nmid$ Professor and Chairman, Department of Anesthesiology, University of Tokyo School of Medicine, Tokyo, Japan. 
Group 1: seven patients who were given nitrous oxide-oxygen-relaxant combined with pentazocine.

Group 2: seven patients who were given low spinal anaesthesia and nitrous oxide-oxygen-relaxant combined with pentazocine.

General anaesthesia was induced with thiopentone and succinylcholine followed by endotracheal intubation. Respiration was controlled with a Bird respirator delivering 70 per cent nitrous oxide and 30 per cent oxygen in a semiclosed system. D-tubocurarine chloride was employed for the maintenance of controlled respiration, respiratory frequency was set at 15 cycles/min, and tidal volume was adjusted to produce a minute volume of about 8 litres for normocarbia. A 22-gauge needle was placed in a branchial artery, and an arterial sample was withdrawn, usually at intervals of 15 minutes during anaesthesia, in $\mathrm{Il}$ patients. Arterial $\mathrm{pH}$ and $\mathrm{PaCO}_{2}$ were measured by the interpolation technique of Siggard-Andersen. ${ }^{16}$ Fifteen $\mathrm{mg}$ of pentazocine was injected intravenously in all patients at an interval of 20 minutes.

\section{Animal Experiments}

Experiments were performed on six adult cats weighing 3.5 to $4.0 \mathrm{~kg}$, under pentobarbital anaesthesia ( $30 \mathrm{mg} / \mathrm{kg}$, intraperitoneal). Epidural electrodes were implanted in the anterior sigmoid gyrus for the cortical (neocortex) recording, and bipolar concentric electrodes were chronically implanted in the hippocampus dorsalis for the tip, of which between 0.5 to $1 \mathrm{~mm}$ was exposed. Other electrodes were also chronically implanted in the mesencephalic reticular formation, posterior hypothalamus, pontine reticular formation, centro-median thalamic nucleus and ventropostero-lateral thalamic nucleus for the local injection of pentazocine. All electrodes were fixed to the skull with dental cement, and experiments were performed 14 days after electrode implantation. Pentazocine $(0.15 \mathrm{mg})$ was injected into the above-mentioned sites of the brain. Injection was performed for about 10 seconds. The injected solution had the following characteristics: $\mathrm{pH} 6.8$ and $0.004 \mathrm{mosm} / \mathrm{micro}$ litre. Controlled injections of the solvent of pentazocine, adjusted for $\mathrm{pH}$ and osmolarity, were also administered. The animals were placed in an observation box with a one-way viewing window. The electrodes were connected to a Nihon-Koden electroencephalograph by a skull plug and a connecting wire. The cats were able to move without restriction within the observation box, and were frequently subjected to pin-prick stimuli before and after the administration of pentazocine into the brain. The accuracy of the electrode placement into subcortical sites was confirmed by subsequent histological examination. The resultant activation was characterized, in the EEG obtained from the neocortex, by a pattern consisting of fast low amplitude waves. Deactivation, on the other hand, was associated with an EEG pattern which was characterized by higher amplitude and slow electrical activity. ${ }^{17}$ Also, hippocampal activation was characterized by a pattern which consists of regular slow waves. Deactivation, on the other hand, is associated with the EEG pattern characterized by the disappearance of the regular slow waves of the hippocampus. ${ }^{18}$ Therefore, our results in this animal study correlated with the generally current definitions of neocortical and hippocampal activated or deactivated patterns of EEG. 


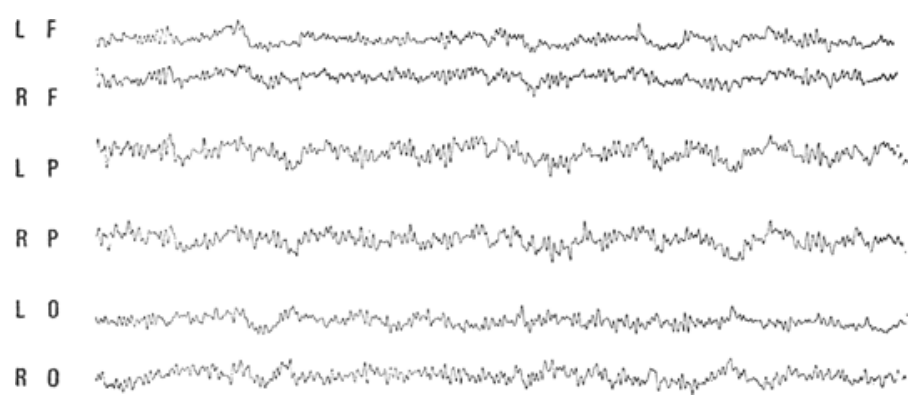

B

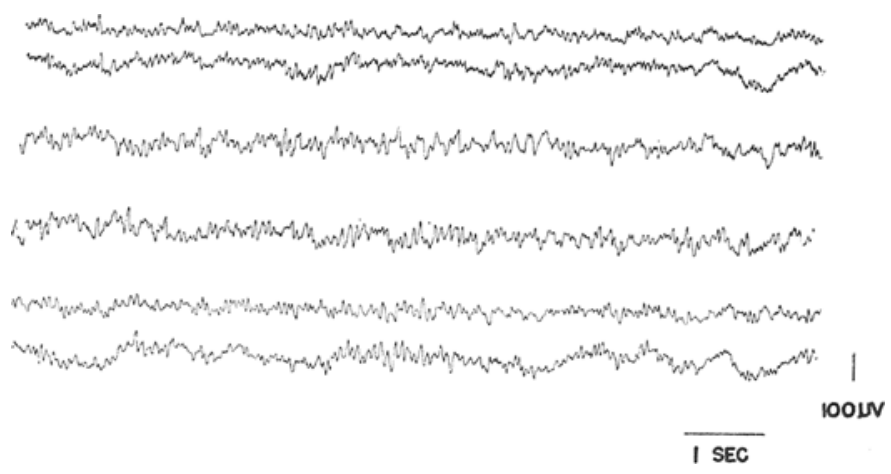

Figure 1. Eeg recordings in a male volunteer 26 years old. From top to bottom; left and right frontal ( $L F, R F$ ), parietal ( $1 P$, RP) and occipital (LO, Ro). A represents the control state; $\mathrm{B}$ was recorded 6 minites after the injection of pentazocine. A slight increase in the fast activity component in both sides of the frontal areas was observed.

\section{Results}

\section{VOLUNTEERS}

After administration of pentazocine intravenously, consciousness remained normal in three subjects. One subject complained of nausea and an uncomfortable feeling. The other complained of drowsiness. The EEG after administration of pentazocine showed no change or increase of fast wave activity in frontal leads regardless of nausea and drowsiness (Figure 1). Blood pressure and pulse rate were maintained within the normal range. Respiratory depression was not observed. The EEg change as shown in Figure 1 continued for about 15 minutes. 
TABLE I

Recording Conditions in Clinical, Cases

\begin{tabular}{|c|c|c|c|}
\hline \multirow[b]{2}{*}{ Subj. } & \multicolumn{2}{|c|}{ pH } & \multirow{2}{*}{$\begin{array}{l}\mathrm{PaCO}_{2} \\
(\mathrm{mmHg})\end{array}$} \\
\hline & mean & S. D. & \\
\hline H. Y & 7.410 & 0.057 & 38.0 \\
\hline A. A & 7.421 & 0.012 & 39.1 \\
\hline S.R & 7.400 & 0.066 & 42.1 \\
\hline$T \cdot N$ & 7.411 & 0.027 & 40.2 \\
\hline O. $\mathrm{K}$ & 7.398 & 0.091 & 43.1 \\
\hline T. K & 7.401 & 0.021 & 41.1 \\
\hline M.S & 7.402 & 0.072 & 36.0 \\
\hline $\mathbf{T} . \mathbf{Y}$ & 7. 399 & 0.066 & 38.1 \\
\hline K. E & 7.399 & 0.028 & 42.1 \\
\hline K. U & 7.402 & 0.031 & 36.0 \\
\hline T. C & 7. 411 & 0.039 & 36.2 \\
\hline M. O & 7.401 & 0.088 & 36.1 \\
\hline R.S & 7.396 & 0.092 & 41.0 \\
\hline $\mathbf{M} . \mathrm{S}$ & 7.394 & 0.065 & 40.0 \\
\hline
\end{tabular}

\section{Clinical Study}

Group 1 Nitrous oxide-oxygen-relaxant combined with pentazocine. Blood pressure and pulse rate were stable during surgical operation. Cyanosis and body movement were not observed, and blood loss was negligible. The anaesthesia time was $90 \pm 16.4$ minutes. Arterial $\mathrm{pH}$ and $\mathrm{PaCO}_{2}$ of all patients was within the normal range. Table I shows the average and standard deviation of measurements of arterial $\mathrm{pH}$ and $\mathrm{PaCO}_{2}$, taken six times. Before the administration of pentazocine, the EEG under nitrous oxide-oxygen anaesthesia showed 2-6 cps, 100-250 microvolts. This EEG pattern changed to $10-15 \mathrm{cps}$ and 50-70 microvolts, following administration of pentazocine intravenously. This EEG pattern continued for about 20 minutes. After recovery from anaesthesia, the patients were not aware that surgery had taken place. 
A
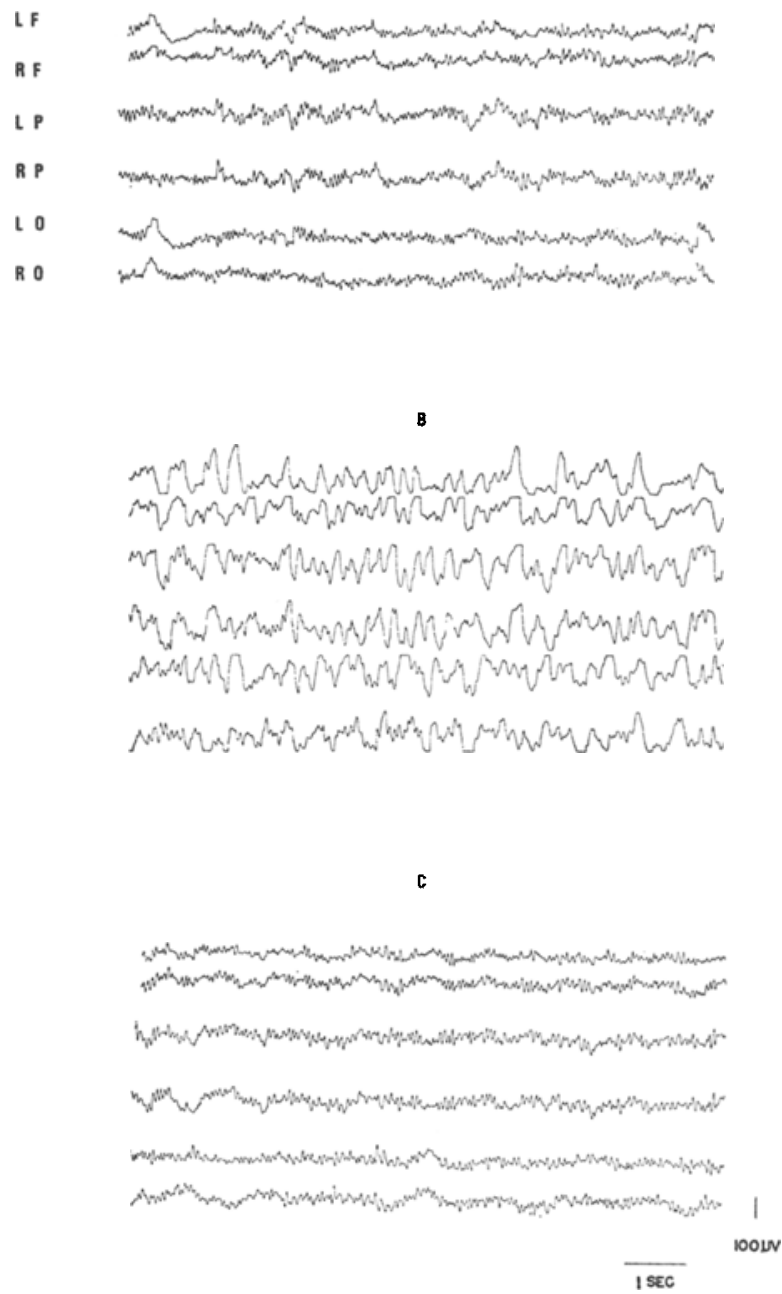

Figure 2. Eeg changes in a male patient 20 years old with left club foot. A represents the condition about 20 minutes after spinal anaesthesia. B was recorded under nitrous oxide-oxygen anaesthesia combined with spinal anaesthesia. $\mathrm{C}$ was recorded about 5 minutes after the injection of pentazocine under spinal anaesthesia combined with nitrous oxide-oxygen anaesthesia. Calibration: $1 \mathrm{sec}$. and 50 micro volts.

Group 2 Nitrous oxide-oxygen-relaxant combined with pentazocine and spinal anaesthesia.

The spinal anaesthetic area was below T-12, and no change of consciousness, blood pressure, pulse rate or respiration were observed after spinal anaesthesia. The EEG did not change after spinal anaesthesia, and under nitrous oxide-oxygenrelaxant anaesthesia following administration of pentazocine, it changed to low voltage fast activity. These EEG findings were the same as group 1. Figure 2 shows electrical recordings from the patient. 
A

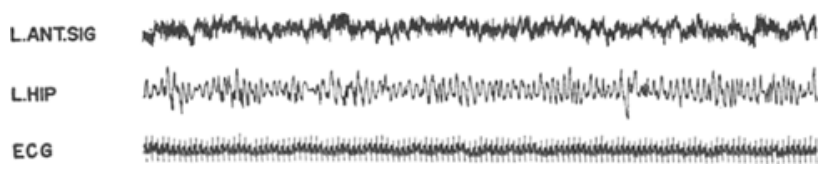

B

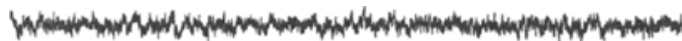
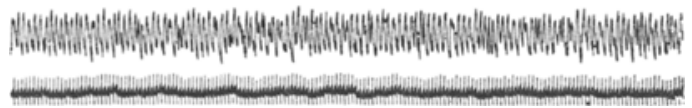

c

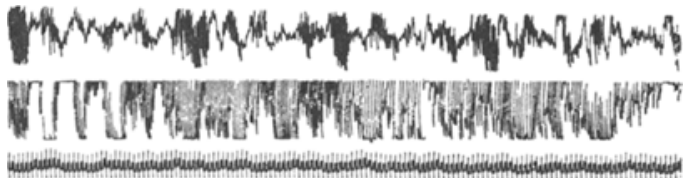

D

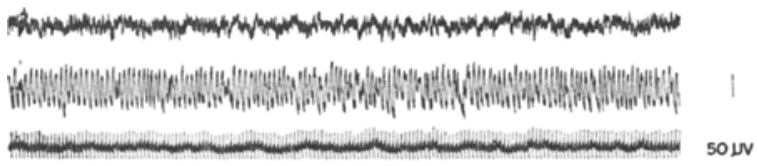

ISEC

Figure 3, L ANT. sIG; the left side anterior sigmoid gyrus, L. HIP; the left side hippocampus dorsalis. A; control state, $\mathbf{B}$ was recorded about 10 seconds after local injection into the mesencephalic reticular formation, $c$; ten seconds after local injection into the posterior hypothalamus, $D$; ten seconds after injection into the pontine reticular formation; note the dissociation phenomenon between the activity of neocortex and hippocampus after the local injection of pentazocine into the posterior hypothalamus (c).

\section{Animal Experiment}

When pentazocine was injected into the mesencephalic and pontine reticular formation, the activated patterns in the neocortex and hippocampus were particularly evident and were more marked than those which were observed prior to pentazocine injection (Figure 3B and $\mathrm{D}$ ). These electoencephalographic findings were observed about 10 seconds after the administration of pentazocine and continued for 15 to 30 minutes. In these cases, the animals were responsive to pin- 


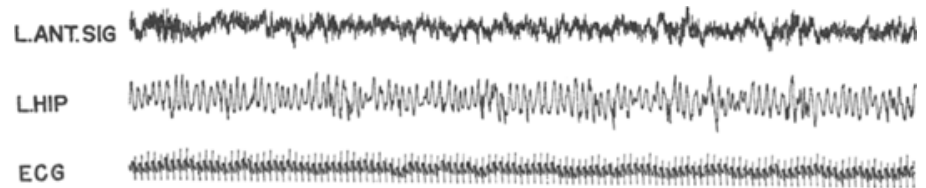

B

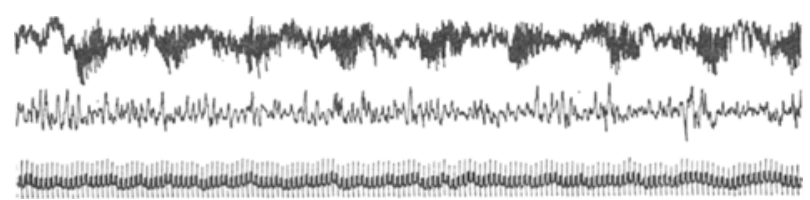

c

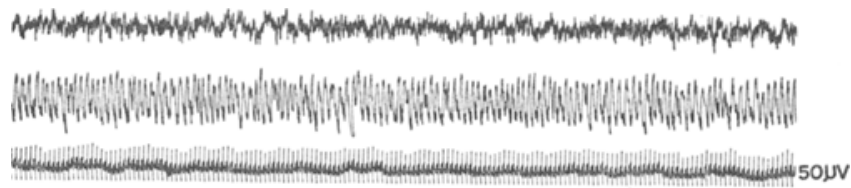

ISEC

Figure 4. A indicates the control state, and $\mathrm{B}$ was recorded about 10 seconds after the local injection into the centro-median thalamic nucleus. The deactivated patterns of neocortical and hippocampal EEG were observed. c was recorded about 3 minutes, after local injection into the ventropostero-lateral thalamic nucleus. The activated patterns of neocortex and hippocampus were observed.

prick stimuli. When pentazocine was injected into the posterior hypothalamus, a dissociation phenomenon between neocortical and hippocampal EeG was observed. The EEG in the neocortex showed a deactivated pattern while seizure pattern was observed in the hippocampal activity (Figure 3c). The animals become unresponsive to pin-prick stimuli, and when pentazocine was injected into the centromedian thalmic nucleus, evidence of scdation was observed. Within ten seconds of injection into the centro-median thalamic nucleus, neocortical and hippocampal deactivated patterns were obtained (Figure $4 \mathrm{~B}$ ), and about one minute after the local injection, the animal became unresponsive to pin-prick stimuli. After 40 to 60 minutes, the animals were behaviourally awake and the EEG returned to the activated patterm spontaneously. Following application of pentazocine to the ventropostero-lateral thalamic nucleus, the electrical activations in the neocortex and hippocampus were caused by the application of pentazocine (Figure 4c). In this case, the animals became responsive to pin-prick stimuli. When $0.15 \mathrm{mg}$ of 
pentazocine was injected intravenously, electrical activities in the neocortex and hippocampus were not changed, nor did the behavior of the cats show any change.

\section{Discussion}

The electroencephalographic effects of pentazocine as shown in Figure 1 are not clear. However, electroencephalographic slowing (deactivated pattern) following the administration of pentazocine was not observed. The EEG shows a tendency to desynchronized rather than synchronized pattern. During anaesthesia, the factors responsible for EEG changes are the depth of anaesthesia, surgical stress, hypoxia, fluctuation of blood pressure, carbon dioxide accumulation, body temperature and so forth. ${ }^{15}$ In our clinical study, these factors were carefully excluded. The respiration of the patients was controlled with muscle relaxant in order to exclude hypoxia and $\mathrm{CO}_{2}$ accumulation. Also, a spinal block was administered to the patients in order to obtain a complete block of pain sensation during surgery. The effects of spinal block and controlled respiration on the EEG can not be ignored. However, the EEg shows a slowing (deactivated pattern) trend under spinal block or controlled respiration. When pentazocine was injected intravenously, the low voltage fast activity (activated pattern) was observed in all patients (Figure 2c). The EEG has been used as an indicator of anaesthetic plane. However the electroencephalographic effects of pentazocine under nitrous oxide-oxygen anaesthesia differ sharply from the patterns of change under ether, halothane, methoxyflurane and cyclopropane anaesthesia. In this study, spinal block and controlled respiration were used to exclude other factors and to define the EEG of pentazocine. In actual practice, it is not necessary to employ spinal block or muscle relaxant. In this case, they were employed to facilitate research. The maintenance of anaesthesia was adequate with nitrous oxide-oxygen and pentazocine except in the case where muscle relaxant proved indispensable. From these results, low voltage fast activity in the EEG following administration of pentazocine during nitrous oxide-oxygen-relaxant anaesthesia will be seen to be due to the pharmacological effect of pentazocine itself. The state of consciousness is known to have a functional relationship with the mesencephalic reticular formation, ${ }^{17}$ hypothalamus, ${ }^{19,20}$ and pontine reticular formation. ${ }^{21,22}$ The pain sensation is known to have a relationship with thalamus. In our animal experiment, the important point is that the pharmacological effect of pentazocine was induced by the local application of pentazocine into the brain. Because of the possibility of electroencephalographic changes due to $\mathrm{pH}$, osmolarity of this drug and mechanical stimulation caused by injection should be considered. Electroencephalographic and behavioural changes were not observed following the controlled injection of the solvent of pentazocine into the brain. Also, no electroencephalographic and behavioural changes were obtained following the administration of $0.15 \mathrm{mg}$ of pentazocine intravenously in animal experiments. Although many problems still await solution we consider that the electroencephalographic and behavioural findings are due to the pharmacological effect of the drug. Other investigators, using a similar method, but investigating other drugs, have reported findings which support this supposition. ${ }^{23}$ When pentazocine, in quantities above $0.25 \mathrm{mg}$ was injected into each of the sites of brain described, the EEG showed the same pattern which was observed 
following administration of $0.15 \mathrm{mg}$ of pentazocine applied locally. But the animals vomited, and sometimes excited behaviour was observed under a relatively large quantity of pentazocine applied locally. When pentazocine below $0.005 \mathrm{mg}$ was injected into the brain, no electroencephalographic and behavioural changes were observed. Following local application of $0.15 \mathrm{mg}$ of pentazocine into the mesencephalic reticular formation, pontine reticular formation and ventroposterolateral thalamic nucleus, the EEG showed the activated pattern. The animals responded behaviourally to pin-prick stimuli. The local application into the centromedian thalamic nucleus consistently reproduced behavioural and electroencephalographic evidence of an analgesic state which was induced by administration of $5 \mathrm{mg}$ of pentazocine intravenously. When pentazocine was applied locally to the posterior hypothalamus, the hippocampal EEG showed seizure activity while the animal was unresponsive to pin-prick stimuli. These facts may suggest that the analgesic state following administration of pentazocine is clue to the inhibition of the non-specific thalamic nucleus and that the activated pattern of EEG following administration of pentazocine during nitrous oxide-oxygen anaesthesia is due to activation of the posterior hypothalamus.

\section{SUMMTATY}

The elcetroencephalogram during anaesthesia with pentazocine and nitrous oxide-oxygen and the site of action of pentazocine in the brain were investigated. The activated pattern of FEG was observed following administration of pentazocine intravenously during nitrous oxide-oxygen anaesthesia in clinical cases. In chronic animal experiments, the activated pattern of EEG was also obtained by local application into the mesencephalic reticular formation, pontine reticular formation and ventropostero-lateral thalamic nucleus. The animals were responsive to pin-prick stimuli. Following the injection into the posterior hypothalamus, necortical deactivation was obtained while a hippocampal seizure pattern was observed, and following the application into the centro-median thalamic nucleus, both the neocortical and hippocampal deactivated patterns were observed. In the case of local application into the posterior hypothalamus and centro-median thalamic nucleus, the animals became unresponsive to pin-prick stimuli.

\section{RÉSUMÉ}

Nous avons étudié les effets de l'anesthésie avec la pentazocine, protoxyde d'azote ct oxygène sur le tracé électroencéphalographique ainsi que le site d'action de la pentazocine dans le cerveau. Dans les cas cliniques, nous avons observé un type activé d'EEg à la suite de l'injection par voie endoveineuse de pentazocine au cours de l'anesthésie au protoxyde d'azote et oxygène. Chez les animaux d'expérience, nous avons également obtenu un type activé de EEG en faisant une application locale dans la formation réticulée mésencéphalique, la formation réticulée pontine et le noyau thalamique ventropostéro-latéral. Les animaux répondaient aux stimulations par piqûres d'épingle. Après injection dans l'hypothalamus postérieur, nous avons obtenu une déactivation néocorticale et avons observé un type d'FEG de convulsion hippocampale et après l'application dans le noyau thalamique centro-médian nous 
avons observé les deux types d'EEG: néocortical et hippocampal déactivé. Lors de l'application locale dans l'hypothalamus postérieur et le noyau thalamique centromédian, les animaux ont cessé de répondre aux stimulations par piqûre d'épingle.

\section{REFERENCES}

1. Ahlgren, E. W. \& Stephen, C. R. Laboratory and Clinical Experience with a New Analgesic - Pentazocine. Anesth. \& Analg., 45: 673 (1966).

2. Brown, A. S. Pentazocine: A Potent Analgesic. Proc. Roy. Soc. Med. 62: 805 (1969).

3. Beaver, W. T.; Wallenstein, S. L.; Houde, R. W.; \& Rogers, A. A Comparison of the Analgesic Effects of Pentazocine and Morphine in Patients with Cancer. Clin. Pharmacol. Ther., 7: 740 (1966).

4. Beaver, W.T.; Wallenstein, S. L.; Houde, R. W.; \& Rogers, A. A Clinical Comparison of the Effects of Oral and Intramuscular Administration of Analgesics: Pentazocine and Phenazocine. Clin. Pharmacol. Ther., 9: 582 (1968).

5. Norris, W. \& Telfer, A. B. M. The Sedative Properties of Pentazocine (Fortral). Brit. J. Anaesth., 40:34I (1968).

6. O’Connell, T. C. J.; Heffernan, S. J.; Lane, D. A. A.; MacMullin, J. P. O.; O'Grady, J. F.; \& Delanex, P. V. A Comparison of the Effects of Pentazocine and Pethidine Injections in Postoperative Pain. J. Irish M. A., 61: 357 (1968).

7. KAY, B.; Keaney, J. P. D.; \& Taylor, G. J. Neuroleptanalgesia: A Double-Blind Comparison of Pentazocine and Phenoperidine for Neuroradiological Investigations. Brit. J. Anaes., 42: 329 (1970).

8. Tammisto, T.; Lahdensuv, M.; \& Fock, G. Pentazocine as a Supplement in Anesthesia: A Clinical Comparison of Pethidine, Fentanyl and Pentazocine in Nitrous Oxide-OxygenRelaxant Anesthesia. Ann. chir. et gynaec. Fenniae, 56:319 (1967).

9. Bellville, J. W. \& Green, J. The Respiratory and Subjective Effects of Pentazocine. Clin. Pharmacol. Ther., 6: 152 (1965).

10. Jennett, S.; Barker, J. G.; \& Forrest, J. B. A Double-Blind Controlled Study of the Effects on respiration of pentazocine, Phenoperidine and Morphine in Normal Man. Brit. J. Anaesth., 40:864 (1968).

11. Lal, S.; Savidge, R. S.; \& ChHabra, G. P. Cardiovascular and Respiratory Effects of Morphine and Pentazocine in Patients with Myocardial Infarction. Lancet., I: 379 (1969).

12. Tammisto, T.; Takki, S.; \& Torkka, P. A Comparison of the Circulatory Effects in Man of the Analgesics Fentanyl, Pentazocine and Pethidine. Brit. J. Anaesth., 42: 317 (1970).

13. Davie, I.; Scott, D. B.; \& Stephen, G. W. Respiratory Effects of Pentazocine and Pethidine in Patients Anaesthetized with Halothane and Oxygen. Brit. J. Anaesth., 42: 113 (1970).

14. Stephen, G. W.; Davie, I.; \& Scott, D. B. Circulatory Effects of Pentazocine and Pethidine during General Anaesthesia with Nitrous Oxide, Oxygen and Halothane. Brit. J. Anaesth., $42: 311$ (1970).

15. Martin, J. T.; Faulconer, A. Jr.; \& Bickford, R. G. Review Article; Electroencephalography in Anesthesiology. Anesthesiology, 20:359 (1959).

16. Siggard-Andersen. The Acid-Base Status of the Blood. The Scandinav. J. Clin. \& Lab. Invest., 15: 70 ( 1963).

17. Moruzzi, G. \& Magoun, H. W. Brain Stem Reticular Formation and Activation of the EEG. Electroencephatog. \& Clin. Neurophysiol., 1: 455 (1949).

18. Green, J. D. \& Aruduin,, A. A. Hippocampal Electrical Activity in Arousal. J. Neurophysiol., $17: 533$ (1954).

19. Gellhonn, E. Physiological Foundations of Neurology and Psychiatry. Minneapolis, Minn: University of Minnesota Press (1953).

20. Tokizane, T.; Kawamura, H.; \& Imamura, G. Hypothalamic Activation upon Electrical Activities of Paleo- and Archiocortex. Neurol. Medicochir., 2: 73 (1960).

21. Jouver, M. Recherches sur les Structures Nerveuses du Sommeil Physiologique. Arch. ital. Biol., 100: 125 ( 1962).

22. Tokrzane, T. Study on the Paradoxical Phase of Sleep in the Cat. In; T. Tokizane and Schade (Eds.) Progress in Brain Research, Amsterdam: Elsevier, 1966, 21 в: 230 ( 1966 ).

23. Leighton, K. M. \& Jenkins, L. C. Experimental Studies of the Central Nervous System Related to Anaesthesia: rv. Effect of Pentobarbital Placement in Caudate Nucleus. Canad. Anaesth. Soc. J., 17: 112 (1970). 